\title{
IX. Observations on the transition of animal or absorbing earth to the state of calcareous earth
}

\section{B.G. Sage}

To cite this article: B.G. Sage (1800) IX. Observations on the transition of animal or absorbing earth to the state of calcareous earth, Philosophical Magazine Series 1, 7:27, 246-247, DOI: $10.1080 / 14786440008562582$

To link to this article: http://dx.doi.org/10.1080/14786440008562582

曲 Published online: 18 May 2009.

Submit your article to this journal $\lceil\pi$

Џ Article views: 2

Q View related articles 


\section{$[246]$}

IX. Obfervations on the Tranfition of animal or abforbing Eartb to tbe State of calcareous Eartb* ${ }^{*}$. By B. G. SAGE Director of the firg Scbool of Mines.

$\mathrm{T}$

THE afhes produced by burht bones are white, and compofed of more than two-thirds of animal earth, and of a part of that fame earth combiried with phofphoric acid. They produce by lixiviation a pretty large quantity of natron, from which the fire, according to all appearance, häs feparated the phofphoric acid.

Bone-alhes ought to be confidered as a phofphoric falt with an excefs of animal earth. Thefe afhes, deprived of their natron by lixiviation, are infipid, and infoluble in water, but the phofphoric falt becontes foluble if it be difengaged from the excers of animal earth with which it is combined, and which may be effected by means of the vitriolic acid. Fourteen parts of this acid concentrated are requifite for twenty-four of bone-d fhes! the more they are calcitical to whitenefs, the latger will be the quantity of vitrifiable phofthotic acid extracted from then. It is contained in them in the proportion of a third. This falt, compofed of animal earth and phofphoric acid, may be decompofed by fixed alkali; which prècipitates from it an infoluble calcareous phofphorous falt. This character of infolubility ferves tó thow that there is a difference between the animal earth and the calcareous earth, firtec the photphoric acid fait, with a bafe of animal earth, is foluble in water. When vitrified, it produces a pellucid mafs of a light bluc tint; while the phofphoric falt with a calcareous bafe produces by fuficn a femitranfparent white glafs, cryftallifed at its furface into a kind of dendrites.

Six ounces of vitrifiable phofphoric acid falt, dried into a foft pafte, required four ounces of fixed alkali of tartar to be

Calcareous tarth differs from that of bones in being compofed of acidum pingue and an exceis of animal earth. Calcination reduces it to lime: but this is not the cafe with the earth of bones, whicts is a phofphoric falt with excers of animal earch. The name of pofphat of lime, giren to the earth of bones, is confequently improper.

decompofetes 
decompofed. The white precipitate, wafhed and dried, weighed one ounce fix drams.

The leys, when evaporated, produced three ounces five drams of phofphoric tartar. This falt, when expofed to heat in a crucible, liquefies, fwells up, and becomes fufed. If it be poured on a plate of iron, it has the tranfparency of glafs as long as it is warm, but becomes white and opake on cooling. This falt when fufed is fapid, and foluble in water: it lofes by fufion three-eighths of its water of cryftallifation.

In the decompofition of the vitriable phofphoric acid falt by fixed alkali, more than half of the alkali is decompofed; fince there are obtained no more than three ounces fire drams of phofphoric tartar, which contain three eighths of water.

The portion of acidum pingue, the principle of the fixed alkali *, which modifies itfelf into mephitic acid gas, is very fmall. This acidum pingue combines with the animal earth, and conftitutes calcareous earth, which faturates itfelf with phofphoric acid, and forms the infoluble falt above mentioned $t$.

X. Account of a new, eajy, and more cowvenient Proces for refolving Minerals by Alkalies. By M. Lowıтz ${ }_{4}^{+}$.

$\mathrm{T}$

HE decompofition of mineral bodies is, without doubt, one of the moft difficult and mot laborious operations of chemiftry, and which muft ftill become more difficult and complex in proportion as we are acquainted with a greater number of new and component parts in foffil bodies; for every new difcovered earth or fpecies of metal requires after-

* When fixed alkali is employed for the precipitation of any fubtance, there is always a part of the alkali decompufed, and the acid and earth contained in it form part of the precipitate. Of this, mercury difengaged from the nitrous acid by tixed alkali affords an inftance. If this precipitate be difilled, it is fublimated into a mercurial falt fui generis. The earth of the alkali remains at the bottom of the retort.

$f$ In the above curious paper the author's own nomenclature has been followed.-Epit.

From Crell's Cbemical Annals, s799, Vol. II. part 10. 